\title{
Correlation of Nutritional Status to Sleep Problems in School Going Children: A Preliminary Study
}

\author{
${ }^{1}$ Yerra Anusha, ${ }^{2}$ Vabitha Shetty, ${ }^{3}$ Amitha M. Hegde
}

\begin{abstract}
Introduction: Sleep disturbances in children are found to be increasing over the past few years and the knowledge about their risk factors is limited among the medical and dental practitioners. Nutritional status could be one of the contributing factors for sleep problems in children.
\end{abstract}

Methodology: 500 school going children aged 4 to 10 years were included in the study. The sleep problems were assessed using a validated sleep questionnaire which was filled by the parents of the children and simultaneously the weight of the children was recorded. The data were documented and statistically analyzed.

Results: Sleep problems were found significantly higher in obese children. Also, a significant association was observed between obesity and the following sleep problems, i.e. snoring, observable lapses in breathing sleeps with mouth open and bed wetting.

Conclusion: Obesity can be considered as one of the risk factor for sleep problems in children.

Keywords: Nutritional status, School going children, Sleep problem

How to cite this article: Anusha Y, Shetty V, Hegde AM. Correlation of Nutritional Status to Sleep Problems in School Going Children: A Preliminary Study. Indian Sleep Med 2018;13(1):1-4.

Source of support: Nil

Conflict of interest: None

\section{INTRODUCTION}

Sleep is very essential for our well-being and survival throughout the life. ${ }^{1}$ It is the power source that keeps the mind alert and calm. ${ }^{2}$ Children, in particular, need adequate and a good quality sleep to develop and function optimally and to meet their scholastic requirements. ${ }^{3}$ Sleep also fuels physical growth. ${ }^{4-6}$

Not much is known about the sleep disturbances in children. over past few years, sleep disturbances in chil-

${ }^{1}$ Post Graduate; ${ }^{2}$ Professor, ${ }^{3}$ Senior Professor and HOD

${ }^{1-3}$ Dept. of Pedodontics and Preventive Dentistry, A.B. Shetty Memorial Institute of Dental Sciences, Deralakatte, Mangalore, Karnataka, India

Corresponding Authors: Yerra Anusha, Room No. 120, Kshema Ladies Hostel, Nitte University, Deralakatte, Mangalore, Karnataka, India, Tel.: 9880456328, e-mail: anu_2y@yahoo. co.in dren are found to be increasing. Studies have shown the rate of occurrence of sleep problems in children varying from 1 to $43 \%$ depending on the technique of survey and the age representation in the investigated cohorts.

However, the knowledge about sleep problems and their risk factors is limited among the medical practitioners and dental practitioners in particular. As there is an increase in the occurrence of sleep problems among children, there is a need for dental and medical practitioners to work in tandem to identify the risk factors and treat the cause. ${ }^{7}$

Nutritional status could be one of the contributing factors for sleep problems in children. Basal metabolic index (BMI) is the most commonly used method to assess the nutritional status in an adult. However, in children measuring BMI is complicated as it keeps changing rapidly with growth. Hence, in children, assessing the weight for particular age and sex is recommended to be an appropriate method for evaluating the nutritional status. $^{8}$

Very few studies have been reported on correlation of nutritional status to sleep problems in children. Hence, the aim of study was to see if there is any significant correlation between the nutritional status and sleep problems in school children.

\section{METHODOLOGY}

Assuming the prevalence of sleep problems to be $40 \%$ (roughly estimated $40 \%$ ), precision of $4.3 \%$, confidence level of $95 \%$, sample size calculated was 499 . Thus a total of 500 children aged 4 to 10 years of either gender were randomly selected from local schools near the institution.

\section{Exclusion Criteria}

- Children on chronic medication

- Children with the following -

口 Psychological/neurological illness

- Muscle weakness

- Genetic disorders

a Metabolic disorders

Ethical clearance for our study was obtained from the ethical committee of our institution.

A structured questionnaire was designed based on the previous studies ${ }^{1,9-11}$ to assess the sleep problems. The questionnaire was validated and modified by experts in 
the subject and also by a pilot study conducted among 10 parents of randomly selected children aged 4 to 10 years in our department.

The following sleep problems were assessed using the questionnaire:

Snoring, noisy breathing, observable lapses in breathing during sleep, frequent awakening, restless sleep, daytime napping, bed wetting, night terrors, sleep talking, sleepwalking and sleeping with mouth open.

Study was explained to the school authorities and parents at parents, teachers meeting. Permission was obtained to carry out the survey from the concerned local educational authorities and parents of the children. Assent was obtained from the children participating in the study.

Parents were divided into small groups and the questionnaire was filled by them under the guidance of a trained investigator in the presence of a staff member. To maintain uniformity, only one investigator recorded all data from the parents. Simultaneously, the weight of the children was also recorded in kilograms using the Avon electronic digital weighing machine.

Nutritional status was assessed using the World Health Organization weight for age pediatric growth chart for boys and girls. The growth chart includes 5 categories of nutritional status of children namely malnourished, underweight, normal weight, overweight and obese which are divided based on the percentiles (malnourished-below 3rd percentile, underweight-3rd to 15 th percentile, normal weight-15th to 85 th percentile, overweight-85th to 97 th percentile and obese-above 97 th percentile). ${ }^{12}$

The data were analyzed on a microcomputer using the SPSS software version 22. Descriptive statistics were recorded in frequency and percentage for qualitative data. The association of BMI with sleep problems were analyzed using Chi-square test. $\mathrm{p}<0.05$ was considered to be statistically significant.

\section{RESULTS}

Parents of 500 children were interviewed and the results were recorded in our modified validated questionnaire.
Our sample comprised of 258 girls (51.6\%) and 242 boys $(48.4 \%)$ with a mean age of $6.49+1.79$ (ranging from 4 to 10 years). The students in our study were distributed from pre-school (LKG) to grade 5 .

Taking pediatric growth chart as reference it was found that 406 children (81.2\%) had an adequate weight for their height whereas 54 children $(10.8 \%)$ were underweight, 17 children (3.4\%) were overweight and 23 children $(4.6 \%)$ were obese.

Analysis of sleep problems showed that up to 232 children (46.4\%) displayed at least one sleep problem, out of which snoring was reported in 21 children (4.2\%), noisy breathing in 8 children (1.6\%), observable lapses in breathing during sleep in 5 children (1\%), frequent awakening in 42 children $(8.4 \%)$, restless sleep in 57 children $(11.4 \%)$, daytime napping in 38 children $(7.6 \%)$, bed wetting in 85 children $(17 \%)$, night terrors in 43 children $(8.6 \%)$, sleep talking in 62 children (12.4\%), sleepwalking in 8 children (1.6\%) and 47 children (9.4\%) sleep with their mouth open.

Out of 54 children who were underweight, 20 (37\%) had sleep problems; out of 406 children with normal weight $189(46.6 \%)$ had sleep problems; out of 17 children with overweight, only $3(17.6 \%)$ had sleep problems and out of 23 obese children, 20 (87\%) had sleep problems. Thus sleep problems were significantly higher in obese children ( $\mathrm{p}<0.001)$ (Table 1$)$.

We also observed a significant association $(\mathrm{p}<0.05)$ between obesity and the following sleep problems i.e. snoring, observable lapses in breathing, sleeps with mouth open and bed wetting (Tables 2 to 5 ).

\section{DISCUSSION}

Sleep problems have been found to be increasing in children during the past few years. ${ }^{7}$ However, there is a lacuna about the role of nutritional status and occurence of sleep problems in children.

In our study, sleep problems were found significantly higher in obese children. In particular, sleep problems such as snoring, observable lapses in breathing, sleeping with mouth open and bed wetting were strongly associ-

Table 1: Association of nutritional status of the child to sleep problems

\begin{tabular}{|c|c|c|c|c|c|}
\hline & & & \multicolumn{2}{|c|}{ Sleep Problems } & \multirow[b]{2}{*}{ Total } \\
\hline & & & Yes & No & \\
\hline \multirow{8}{*}{$\begin{array}{l}\text { Nutrition } \\
\text { status }\end{array}$} & \multirow[t]{2}{*}{ Underweight } & Count & 20 & 34 & 54 \\
\hline & & $\%$ within BMI & 37.0 & 63.0 & 100.0 \\
\hline & \multirow[t]{2}{*}{ Normal } & Count & 189 & 217 & 406 \\
\hline & & $\%$ within BMI & 46.6 & 53.4 & 100.0 \\
\hline & \multirow[t]{2}{*}{ Overweight } & Count & 3 & 14 & 17 \\
\hline & & $\%$ within BMI & 17.6 & 82.4 & 100.0 \\
\hline & \multirow[t]{2}{*}{ Obese } & Count & 20 & 3 & 23 \\
\hline & & $\%$ within BMI & 87.0 & 13.0 & 100.0 \\
\hline
\end{tabular}

Chi-Square $=22.77 p<0.001$ (significant) 
Table 2: Association of nutritional status of the child to snoring

\begin{tabular}{|c|c|c|c|c|c|}
\hline & & & & & \\
\hline & & & Yes & No & Total \\
\hline Nutrition status & Underweight & Count & 2 & 52 & 54 \\
\hline & & \% within BMI & 3.7 & 96.3 & 100.0 \\
\hline & Normal & Count & 15 & 391 & 406 \\
\hline & & $\%$ within BMI & 3.7 & 96.3 & 100.0 \\
\hline & Overweight & Count & 0 & 17 & 17 \\
\hline & & $\%$ within BMI & 0.0 & 100.0 & 100.0 \\
\hline & Obese & Count & 4 & 19 & 23 \\
\hline & & $\%$ within BMI & 17.4 & 82.6 & 100.0 \\
\hline
\end{tabular}

Chi-square $=10.983 p=0.012$ (significant)

Table 3: Association of nutritional status of the child to observable lapses in breathing

\begin{tabular}{|c|c|c|c|c|c|}
\hline & & & \multicolumn{2}{|c|}{ Observable lapses in breathing } & \multirow[b]{2}{*}{ Total } \\
\hline & & & Yes & No & \\
\hline \multirow[t]{8}{*}{ Nutrition status } & Underweight & Count & 1 & 53 & 54 \\
\hline & & $\%$ within BMI & 1.9 & 98.1 & 100.0 \\
\hline & Normal & Count & 2 & 404 & 406 \\
\hline & & \% within BMI & 0.5 & 99.5 & 100.0 \\
\hline & Overweight & Count & 0 & 17 & 17 \\
\hline & & \% within BMI & 0.0 & 100.0 & 100.0 \\
\hline & Obese & Count & 2 & 21 & 23 \\
\hline & & $\%$ within BMI & 8.7 & 91.3 & 100.0 \\
\hline
\end{tabular}

Chi-square $=15.382 p=0.002$ (significant)

Table 4: Association of nutritional status of the child to sleeping with mouth open

\begin{tabular}{|c|c|c|c|c|c|}
\hline & & & Sleep & $h$ open & \\
\hline & & & Yes & No & Total \\
\hline Nutrition status & Underweight & Count & 3 & 51 & 54 \\
\hline & & \% within BMI & 5.6 & 94.4 & 100.0 \\
\hline & Normal & Count & 36 & 370 & 406 \\
\hline & & $\%$ within $\mathrm{BMI}$ & 8.9 & 91.1 & 100.0 \\
\hline & Overweight & Count & 0 & 17 & 17 \\
\hline & & \% within $\mathrm{BMI}$ & 0.0 & 100.0 & 100.0 \\
\hline & Obese & Count & 8 & 15 & 23 \\
\hline & & \% within BMI & 34.8 & 65.2 & 100.0 \\
\hline
\end{tabular}

Chi-square $=20.236 p<0.001$ (significant)

Table 5: Association of nutritional status of the child to bed wetting

\begin{tabular}{|c|c|c|c|c|c|}
\hline & & & \multicolumn{2}{|c|}{ Bed wetting } & \multirow[b]{2}{*}{ Total } \\
\hline & & & Yes & No & \\
\hline \multirow[t]{8}{*}{ Nutrition status } & Underweight & Count & 3 & 51 & 54 \\
\hline & & $\%$ within BMI & 5.6 & 94.4 & 100.0 \\
\hline & Normal & Count & 69 & 337 & 406 \\
\hline & & $\%$ within BMI & 17.0 & 83.0 & 100.0 \\
\hline & Overweight & Count & 0 & 17 & 17 \\
\hline & & $\%$ within BMI & 0.0 & 100.0 & 100.0 \\
\hline & Obese & Count & 13 & 10 & 23 \\
\hline & & $\%$ within BMI & 56.5 & 43.5 & 100.0 \\
\hline
\end{tabular}

Chi-square $=33.955 p<0.001$ (significant)

ated with obese children. These findings are supported by Susan Redline et al. ${ }^{13}$ who demonstrated obesity as a risk factor for sleep-disordered breathing in children. This could be because when a child gains weight, the adequacy of the airway is compromised because of the deposition of extra adipose tissue. The degree of obesity varies inversely with the degree of intrinsic inadequacy of the pharyngeal anatomy. ${ }^{14}$

However, our study has certain limitations that need to be acknowledged. Firstly, sleep problems were 
recorded based on the information given by the parents which was based on their level of understanding the question; awareness about their child's sleeping pattern and also their willingness to reveal the appropriate information. However, this is a common bias in most of the questionnaire based studies and as ours was a preliminary study, which we felt it necessary as an initial step to see if any significant correlation exists between nutritional status and sleep problems.

Secondly, the number of obese children in our study sample was very small. Thus further research needs to be carried out on screening large number of children followed by an appropriate examination, diagnosis, and intervention.

\section{CONCLUSION}

We found sleep problems in children belonging to all categories of nutritional status. However, significantly higher frequency of sleep problems were seen in obese children. In particular, sleep problems such as snoring, observable lapses in breathing, sleeping with mouth open and bed wetting were strongly associated with obese children.

\section{REFERENCES}

1. Spruyt K, O'Brien L, Cluydts R, Verleye G, Ferri R. Odds, prevalence and predictors of sleep problems in school-age normal children. Journal of Sleep Research. 2005; 14(2):163176.

2. Cold F, Health E, Disease H, Management P, Conditions S, Problems S et al. Good, Sound Sleep for Your Child [Internet]. WebMD. 2017. Available from: http:/ / www.webmd. com/children/features/good-sound-sleep-for-children\#1

3. Paavonen E, Aronen E, Moilanen I, Piha J, Räsänen E, Tamminen $\mathrm{T}$ et al. Sleep problems of school-aged children: a complementary view. Acta Paediatrica. 2000; 89(2):223-228.

4. Chervin R, Dillon J, Bassetti C, Ganoczy D, Pituch K. Symp- toms of Sleep Disorders, Inattention, and Hyperactivity in Children. Sleep. 1997; 20(12):1185-1192.

5. Wiggs L, Stores G. Severe sleep disturbance and daytime challenging behaviour in children with severe learning disabilities. Journal of Intellectual Disability Research. 1996; 40(6):518-528.

6. Kahn A, Van de Merckt C, Rebuffat E, Mozin MJ, Sottiaux M, Blum D, Hennart P. Sleep problems in healthy preadolescents. Pediatrics. 1989 Sep 1; 84(3):542-546.

7. Ipsiroglu O, Fatemi A, Werner I, Paditz E, Schwarz B. Self-reported organic and nonorganic sleep problems in schoolchildren aged 11 to 15 years in vienna. Journal of Adolescent Health. 2002; 31(5):436-442.

8. Dinsdale H, Ridler C, Ells LJ. A simple guide to classifying body mass index in children. National Obesity Observatory: Oxford, UK. 2011.

9. Hammam AB, AlFaris E, Shaikh S, Saeed AB. Prevalence of sleep problems and habits in a sample of Saudi primary school children. Annals of Saudi medicine. 2006 Jan 1; 26(1):7.

10. Owens JA, Maxim R, Nobile C, McGuinn M, Msall M. Parental and self-report of sleep in children with attentiondeficit/hyperactivity disorder. Archives of pediatrics and adolescent medicine. 2000 Jun 1; 154(6):549-555.

11. Chervin RD, Hedger K, Dillon JE, Pituch KJ. Pediatric sleep questionnaire (PSQ): validity and reliability of scales for sleep-disordered breathing, snoring, sleepiness, and behavioral problems. Sleep medicine. 2000 Feb 1; 1(1):21-32.

12. WHO Multicentre Growth Reference Study Group (2006). WHO Child Growth Standards: length/height-for-age, weight-for-age, weight-for-length, age weight-for-height and body mass index-for-age: methods and development. Geneva: World Health Organisation. www.who.int/ childgrowth/standards/weight_for_age/en/index.html.

13. Redline S, Tishler PV, Schluchter M, Aylor J, Clark K, Graham G. Risk factors for sleep-disordered breathing in children: associations with obesity, race, and respiratory problems. American journal of respiratory and critical care medicine. 1999 May 1; 159(5):1527-1532.

14. Thorton WK, Roberts H. Non surgical management of obstructive apnea patients. J Oral Maxillofac Surg. 1996; 54:1103-1108. 